\title{
Antonio Aliprandi, un estucador lombardo en la Valencia de 1700 *
}

\author{
Pablo González Tornel **
}

\begin{abstract}
RESUMEN
ABSTRACT

$2 \sin 2004$

En torno a 1700 aparecen en Valencia varios artistas extranjeros que residirán

en la ciudad varios años dejando en ella un considerable volumen de obras.

Uno de ellos, Antonio Aliprandi, se especializará en la factura de revestimientos de estuco para interiores principalmente eclesiásticos. En el presente texto se realiza un recorrido por las obras de Aliprandi en Valencia y se documentan varias de ellas hasta el momento sólo atribuidas a su mano.

Arround 1700 many foreign artists appear in Valencia where they will stand for several years leaving in our town quite a lot of handcrafts. One among them, Antonio Aliprandi, will specialize himself on recovering many buildings with stucco, mainly in churches. This text makes a journey along Aliprandi's art pieces in Valencia after working on files to find the documents refered to them.
\end{abstract}

La figura de Antonio Aliprandi, como la de tantos individuos que se movieron en categorias artísticas tradicionalmente consideradas más cerca del artesanado que del arte "tout court", ha sidu fruto de un tratamiento historiográfico muy marginal, siendo siempre englobado dentro de fenómenos artísticos de mayor calado de los que sólo se consideraba una pieza más. Este fenómeno de globalización de un grupo amplio de artistas

* El presente artículo forma parte de la tesis doctoral en curso del autor que incluirá la figura de Antonio Aliprandi y de otros artistas extranjeros activos en la Valencia de la época barroca dentro de un contexto más amplio.

** Universitat de València. 
no ocurre exclusivamente con los artistas lombardos, pero sin embargo es cierto que esta visión de conjunto del arte del norte de la Lombardia, unido geográficamente a la vertiente suiza de los Alpes, ha sido tradicionalmente homogeneizado por la historiografía italiana ${ }^{1}$.

Se ha puesto en relieve la emigración como característica endémica de los artistas en torno al lago Lugano y se ha profundizado en el conocimiento de las áreas geográficas a las que se dirigieron, pero en el proceso, y salvando algunos casos como los de Carlo Maderno o Borromini, se ha perdido el carácter individual de cada uno de ellos. La realidad de estos artistas, más artesanos de calidad que verdaderos creadores, orienta su tratamiento como unidades familiares o poblacionales en las que pocas veces se considera importante el nombre propio del individuo. Sin embargo, y a pesar de lo cierto del proceso migratorio y de la frecuente homogeneidad estilistica, hay factores que hacen que en muchos casos la presencia individual de un artista lombardo en concreto tenga gran significación para la ciudad que le recibe.

Estos artistas supusieron, en muchos casos, para lugares alejados de los principales centros creativos, la llegada de tendencias y técnicas que de otro modo hubieran sido difícilmente conocidas. En el momento que nos interesa, en torno a 1700, la dispersión de arquitectos y estucadores del norte de Lombardía por casi toda Europa no debe ser menospreciada como elemento difusor de ciertas novedades gestadas en ámbito romano varias décadas antes ${ }^{2}$, y desde este punto de vista el individuo y su bagaje artístico cobran importancia.

\footnotetext{
Fundamental en esta construcción historiográfica es la publicación de las actas del congreso Arte e artisti dei Laghi Lombardi. Como, 1959-1964. Véanse también al respecto Morpurgo. Enrico, "ll secolo XVII». L'opera del genio italiano all'estero. Gli artisti in Austria. volumen II, Roma, 1962; Cavarocchi. Franco, Arte e aristi della Valle Intelvi con note storiche-geografiche. Como. 1992; Brentani, Luigi, Antichi maestri darte e di scuola delle terre ticinesi, Como, 1937-1963. COPPA, Simonetta, Civilta artistica in Valtellina e Valchiavenna. II Settecento. Bérgamo, 1994: LANGE, Santino y PACCiarotTI, Giuseppe, Barocco Alpino. Arte e architettura religiosa del Seicento: spazio e figuratività, Milán, 1994. Si bien es cierto que salvo casos puntuales la tendencia mantenida en estas publicaciones es la visión de conjunto sin matizaciones individuales, también lo es que siguen siendo fundamentales para aproximarse al conocimiento de muchos arquitectos, escultores y estucadores de la zona de los lagos.

Para una visiórı general de la magnitud de la dispersión geográfica de los estucadores lombardos durante la Edad Moderna véase BEARD, Geotrey, Stuck, die Entwicklung plasticher Dekoration, deutsche übersetzung, Herrsching, 1983. Una visión más actualizada que revisa el mito de los "magistri comacini" y hace especial hincapié en la ciudad de Génova como foco receptor de las corrientes migratorias en las actas del congreso Magistri d'Europa. Eventi, relaziani, strutture della migrazione di artisti e costruttori dei laghi lombardi, Milán, 1996. En cuanto al conocimiento de las novedades romanas en el siglo XVII, si bien en muchos casos se trataba de conocimientos de segunda o tercera mano, gran cantidad de artistas lombardos pasaron temporadas en la capi tal papal. Véase para ello BERTOLOTTI, A., "Secolo XVII". Artisti lombardi a Roma nei secoli xV, xVI, xwi. volumen II, Milán, 1881 (edición en Sala Bolognese, 1985).
} 
El estucador Antonio Aliprandi (1654-1718) ha sido tratado de este modo por la historiografía. Miembro de una familia dedicada al arte oriunda de Laino en la diócesis de Como y hermano de Giovanni Battista y Lorenzo, ambos artistas, su figura se haya muy diluida, y sobre todo ensombrecida por su hermano Giovanni Battista Aliprandi, arquitecto de cierta fama en Bohemia ${ }^{3}$. Antonio se desplazó por Italia, Austria y España, en un periplo geográfico mucho más amplio que la mayoría de sus contemporáneos, cosa que no se explica sin una igual de rica trama de relaciones personales, y dejó un considerable volumen de obra que nunca ha sido afrontado de forma integral. La inmersión en el conjunto de estucadores lombardos que se movieron por Europa durante estos años ha inducido a una despersonalización historiográfica de su quehacer artístico y su devenir personal. En Italia las referencias a su persona son anecdóticas, la historia del arte austriaca lo ha tratado de forma local, sin profundizar en el resto de su trayectoria, y en cuanto al tratamiento que se le ha dado en la historiografía hispana, y en concreto valenciana, en raras ocasiones se ha superado el simple análisis estilístico de su producción, por otro lado hasta ahora no documentada, mostrando una completa despreocupación por su trayectoria y significación. En esta primera aproximación a la figura de Antonio Aliprandi nos enfrentaremos a la obra que éste dejó en Valencia, emprendiendo un primer paso para darle una cierta solidez historiográfica. Aproximadamente en torno a 1700 Antonio Aliprandi aparece en la ciudad de Valencia, permaneciendo en tierras hispanas al menos hasta 1705. No resulta fácil desentrañar los mecanismos por los que Aliprandi, un estucador lombardo con una fecunda carrera artística en Austria, emprende un viaje hasta la ciudad de Valencia. De todos modos intentaremos aclarar las circunstancias históricas y personales que pueden ayudar a explicar su presencia en nuestra ciudad.

Hay un punto que es difícil obviar, y es su relación con el Archiduque Carlos, futuro emperador Carlos VI de Austria. A pesar de que el Archiduque no llegaría a Valencia hasta varios años más tarde, se hace extraño creer que la presencia de dos artistas que figurarian en la nómina de artistas imperiales no este relacionada directamente con Carlos de Austria. Tanto Conrad Rudolph ${ }^{4}$ como Antonio Aliprandi ${ }^{5}$ están documentados

\footnotetext{
Véase al respecto Nankova, Vera. "G. B. Aliprandi, architetto di Laino in Valle Intelvi", Arte Lombarda, 1966, págs. 135-142.

4 StaATARChIV Wien (S. W.), Hofparteienprotokollen, 221, fol. 37r-38v. 16 diciembre 1713. En este documeto Rudolph aparece nombrado por primera vez como arquitecto y escultor imperial, cobrando sueldo desde el 1 de noviembre de 1707 en España.

5 Saller, Leopold, Die Stukkateure, Viena, 1943, pág. 64, sitúa a Aliprandi cobrando de las arcas imperiales a partir de 1703.
} 
dentro de los artistas al servicio de la corte austríaca, y ambos aparecen de nuevo en Viena tras la vuelta del Archiduque. Por ello parece lógico que su presencia contemporánea en la ciudad de Valencia esté relacionada con la del propio Archiduque Carlos. Por otro lado, las obras en las que encontramos activo a Aliprandi durante los años precedentes a su venida a Valencia se vinculan directamente con la corona, es el caso de Heiligenkreuz, de patronato imperial, o con las estructuras de poder vienesas, el caso del Ayuntamiento, en el que por otro lado las obras realizadas giran igualmente en torno a la figura imperial. Sin embargo la presencia del futuro emperador no es óbice para que haya ciertos personajes del medio valenciano que pudieron facilitar la venida de Aliprandi.

Por un lado se encuentran las figuras de los canónigos ilustrados Antonio Pontons y Vicente Vitoria, con canongías en Valencia y Xátiva respectivamente. Ambos relacionados con el medio italiano y con contactos frecuentes con Génova, Florencia o Roma ${ }^{6}$, y por otro la figura del que desde 1700 era arzobispo de Valencia Antonio Folch de Cardona ${ }^{7}$ quien con la marcha de Carlos de Austria pasará con él a Viena presidiendo el Consejo de España. No olvidemos por otra parte que durante los años de prelatura de Folch de Cardona se emprende por parte del cabildo catedralicio valenciano la obra de la fachada principal cuyo proyecto es obra del ya nombrado Conrad Rudolph.

La referencia básica para conocer la obra de Aliprandi en Valencia es el conjunto de biografías de Marcos Antonio de Orellana ${ }^{8}$, quien afirma que trabajó en la Capilla de la Purísima Concepción de la Casa Profesa de la Compañía de Jesús en Valencia y en la parroquial de San Pedro de la Catedral. Le supone de nacionalidad alemana y, según sus datos, llegó a Valencia con "Conrado Rodulfo", el autor del proyecto de la fachada ca-

6 Sobre el canónigo Vitoria veanse BASSEGODA I HUGAS, Bonaventura. "Noves dades sobre el canonge Vicente Vitoria (Dènia 1650-Roma 1709), tractadista, pintor, grabador i colleccionista". Butleti del MNAC. 2, 1992. págs. 38-62; BASSEGODA I HuGAS, Bonaventura. "Vicente Vitoria (16501709), primer historiador de Joan de Joanes", Locus Amoenus, 1995, págs. 165-172, y BASSEGODA I HUGAS, Bonaventura. "Vicente Vitoria (Denia 1650-Roma 1709), coleccionista de estampas y estudioso de la obra grabada a partir de Rafael», XI Congreso del CEHA. El Mediterráneo y el arte español, Valencia, 1996, págs. 219-22. Sobre el canónigo Antonio Pontons véanse Carijana, J. "Pontons", Almanaque de las Provincias, 1914, págs. 177-185; Buli, Eduardo. "Estampas valencianas: Pontons", en Valencia Atracción 109, 1935, págs. 136-137, y ALDANA NACHER, Cristina. "Mecenazgo y mundo clásico: el ejemplo valenciano del canónigo Pontons", en Actas del X Congreso del CEHA. Los clasicismos en el arte español. Valencia, 1994, págs. 383-389

Garcia Gomez, María Dolores, El arzobispo de Valencia Folch de Cardona. Análisis de una biblioteca eclesiástica del siglo xvm. Alicante, 1996.

8 Orellana, Marcos Antonio de, Biografía pictorica valentina, siglo xvill, Madrid, edición de Xavier de Salas, 1930 , págs. 586 y 588 
tedralicia. El mismo Orellana al hablar de otro de los artistas extranjeros que aparecen en Valencia en el cambio de siglo, Giacomo Bertesi ${ }^{9}$, además de las obras que le atribuye en la Parroquia de San Juan del Mercado y en la casa del canónigo Pontons, afirma que son obra suya «los adornos y retablo de la Concepción de la antes Casa Profesa de la Compañía». En cuanto a esta obra en concreto, el barón de Alcahali es más concreto y separa en la obra de esta capilla la actividad de Bertesi y la de Aliprandi, dando al primero sólo el retablo ${ }^{10} \mathrm{y}$ al segundo sólo los adornos de la capilla ${ }^{11}$.

Además de estas dos obras que tradicionalmente se asociaban a la mano de Antonio Aliprandi, otros autores han contribuido a acrecentar la obra conocida de Aliprandi en tierras valencianas. En primer lugar Juan Gil Gay ${ }^{12}$, a comienzos de siglo, y disponiendo aún de los fondos del archivo parroquial de San Juan del Mercado, sitúa a Aliprandi en dicha parroquia trabajando en los estucos del interior de la nave y en la imagen de la Virgen que hay en la fachada hacia la Plaza del Mercado, también obra de estuco. En ambos trabajos Aliprandi colaboraria con otro extranjero, Giovanni Giacomo Bertesi, quien según la información proporcionada por Gil Gay parece que se dedicaría a las labores escultóricas mientras que Aliprandi le asistiría en los aspectos decorativos ${ }^{13}$. La misma distribución de tareas que mantendria Tormo pocos años después ${ }^{14}$ (Figs. 1 y 2 ).

Orellana, Marcos Antonic de, op. cit., pág. 251.

AlCAHALi, Barón de, Diccionario biográfico de artistas valencianos, Valencia, 1897, pág. 354.

AlCaHal, Barón de, op. cit, pág. 345.

12 Gll GaY, Juan. Monografía histórico descriptiva de la Real parroquia de los Santos Juanes de Valencia, Valencia, 1909, págs. 8 y 11.

13 Sobre el templo destacamos la siguiente bibliografía: BéRCHez Gomez, Joaquín, "Aspectos del barroco arquitectórico en la iglesia de los Santos Juanes de Valencia", Archivo de Arte Valenciano, 1982, págs. 48-53, que comenta algunos aspectos de la reforma exterior del templo que resultan innovadores para la Valencia de finales del XVII; GaLARZA TORTAJADA, M., El templo de los Santos Juanes de Valencia, Valencia, 1990; López Azorín, María José. "Algunos documentos sobre la reforma barroca del templo de los Santos Juanes", Archivo de Arte Valenciano, 1994, págs. 69-75, que permite conocer el nombre de muchos de los artífices materiales de dicha reforma; Gavara Prior, Juan J., "Iglesia parroquial de los Sanios Juanes (Valencia)", en Bérchez Gómez, Joaquín y otros. Monumentos de la Comunidad Valenciana. T. X: Valencia. Arquitectura Religiosa, Valencia, 1995, págs. 76-89, donde se recoge toda la información sobre el templo y se analizan datos tan interesantes como los componentes de la junta de efectos de la parroquia, fundamental a la hora de explicar ciertas opciones artísticas; VILAPLANA. David. Arte e historia de la iglesia de los Santos Juanes de Valencia, Valencia, 1996, estudio pormenorizado de la obra y sus bienes muebles; SEBAStian, Santiago y otros. Visión cultural del templo de los Santos Juanes de Valencia, Zaragoza, 1998, en el que se iratan temas tan diversos como la música o la iconografia en esta iglesia; Sebastian Lopez, Santiago y ZarRanz DOMÉnECH, Maria Reyes, Historia y mensaje del templo de los Santos Juanes, Valencia, 2000, $2 .{ }^{a}$ edición, libro centrado en las interpretaciones iconográficas de los programas pictórico y escultórico de la iglesia

14 Tormo, Elias. Levante, Madrid, 1923, pág. 116. 


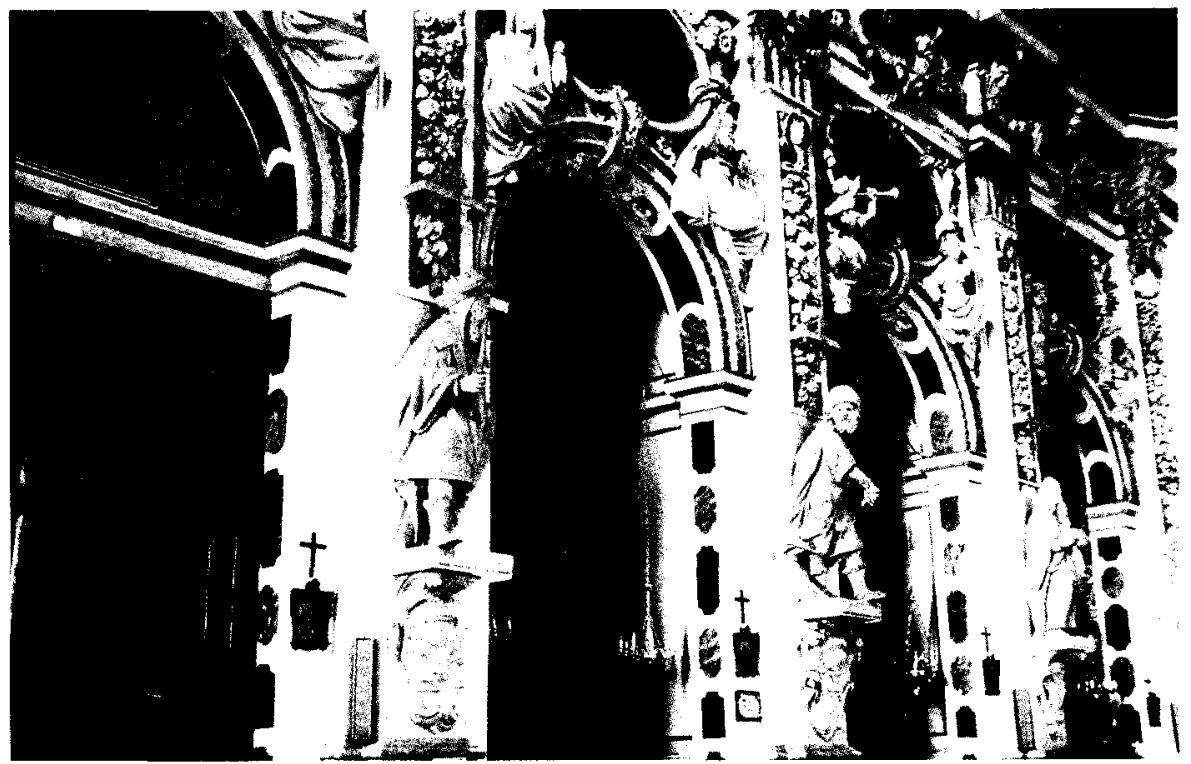

Fig. 1. Interior del Templo de los Santos Juanes. Estucos de Antonio Aliprandi y Giacomo Bertesi.

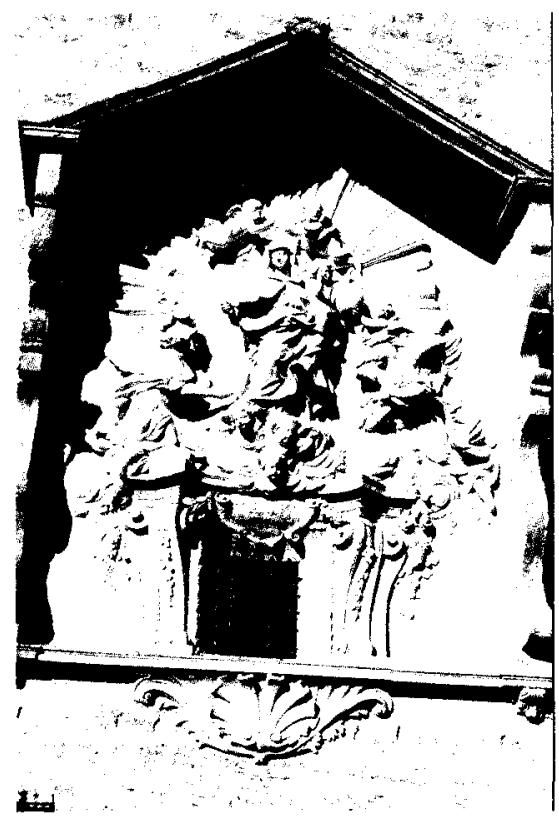

Fig. 2. Virgen del Rosario. Templo de los Santos Juanes. Giacomo Bertesi. 
El interior de la iglesia de los Santos Juanes es un espacio uninave con capillas laterales entre los contrafuertes. A partir de 1693 se decidió voltear una bóveda de cañón con lunetos y convertirla en un espacio ordenado a la clásica ocultando la construcción gótica. El espacio de la bóveda se reservó para las pinturas al fresco que realizarian primero los hermanos Guilló y que terminaría Palomino ${ }^{15}$, y los paramentos laterales, que debian organizar con criterios de ordenación clásica los ingresos a las capillas, según las noticias recogidas por Gil Gay, se confiaron a Giovanni Giacomo Bertesi ${ }^{16}$. La obra que aparece ante nuestros ojos en los muros interiores de San Juan del Mercado es una elaborada obra de estuco en la que las pilastras de orden compuesto se alternan con los vanos de medio punto de las capillas. Entre el arco de las capillas y el entablamento que apoya sobre las pilastras y recorre todo el perímetro de la nave se sitúan óvalos con escenas pictóricas, obra también de Palomino, y dentro del entablamento, a razón de una sobre cada capilla, aparecen una serie de cartelas de formas diversas pero que generalmente tienden al óvalo. Esto en cuanto a la ordenación, pero la obra se completa con una serie de estatuas de bulto. Sobre los arcos de ingreso a las capillas apoyan una serie de esculturas sedentes, dos por arco, y de la base de cada pilastra surge una ménsula sobre la que apoya una escultura que queda situada a media altura, por encima de los ojos del espectador. Todo esto se decora con motivos florales en estuco que llenan los paños vacíos, incluidos los netos de las pilastras. El resultado es un conjunto que combina por un lado una ordenación clara a la clásica con un considerable abigarramiento de motivos decorativos y una fuerte presencia de la escultura (Fig. 3).

En el aspecto iconográfico, en el que no nos detendremos demasiado por haber sido ya objeto de estudios específicos ${ }^{17}$, la aportación principal

15 Respecto a la intervención de Antonio Palomino en los Santos Juanes y en otros templos de Valencia, así como para sus relaciones con los pintores autóctonos y la renovación del estilo pictórico empleado, para decorar interiores eclesiásticos que su obra supone en Valencia, véase LloRENS, Juan Vicente, Antonio Palomino i la pietat valenciana del segle Xvil, Valencia, 1990.

16 Coppinł FAticati, Cele. Giacomo Bertesi. Gli stucchi di Valencia, Cremona, 1999. Este libro, obra de una estudiosa local de la obra de Bertesi, recoge abundante documentación gráfica sobre el aspecto del interior de la parroquia de San Juan del Mercado antes de la Guerra Civil y ayuda a hacerse una idea de la imagen del mismo antes de los destrozos del conflicto. Se centra en el estudio de los estucos atribuidos a Bertesi manteniendo sin cambios las atribuciones e interpretaciones tradicionales.

Alonso Fernandez, Antonio, "El tema de las doce tribus en el templo de los Santos Juanes de Valencia», Traza y Baza, 4, 1974, págs. 29-42, y SEBASTIÁN, Santiago, Contrarreforma y Barroco. Madrid, 1989, págs. 127-131. Las estatuas corresponden a Jacob, Rubén, Leví, Simeón, Judá, Dan, Isacar, Zabulón, Gad, Aser, Neítalí, José y Benjamín. Las alegorías se han identificado con la Anunciación y la Santificación, la Esterilidad y la Fecundidad, la Puericia y la Senectud, el Conocimiento y la 


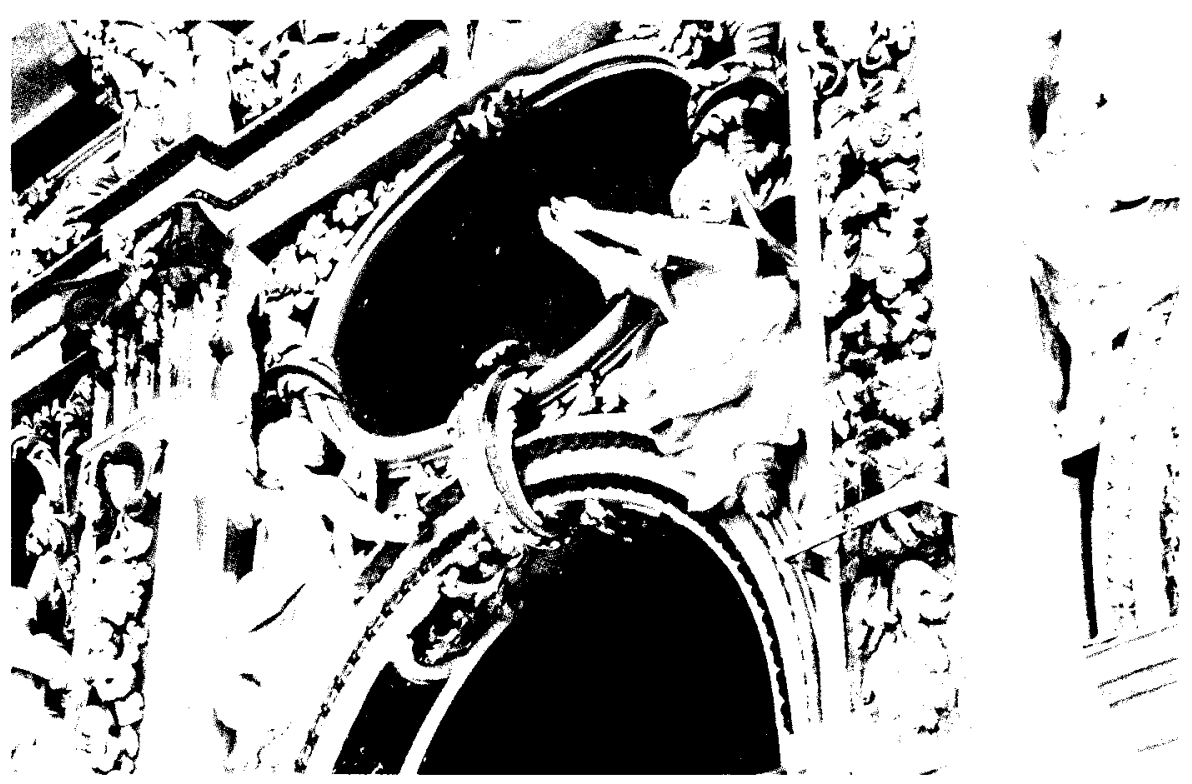

Fig. 3. Interior del Templo de los Santos Juanes. Estucos de Antonio Aliprandi y Giacomo Bertesi.

del estuco lo constituyen las esculturas sobre arcos y ménsulas. Las trece estatuas que sobresalen a media altura sobre las pilastras representan a Jacob y a sus hijos, es decir a las doce tribus de Israel, y las figuras sedentes sobre las capillas son figuras alegóricas de virtudes. Las imágenes de Jacob y sus hijos se han hecho derivar de una serie de grabados de Jan Sadeler ${ }^{18}$ y las figuras alegóricas que reposan en los arcos de Cesare Ripa ${ }^{19}$. Pero lo que menos nos interesa de esta serie de esculturas es el origen de su iconografía, sino sus características formales y lo que su inclusión en un espacio sacro supone. Comparando el interior de Santos Juanes con cualquiera de los interiores valencianos que se redecoraban durante estos años el signo estilístico es totalmente distinto ${ }^{20}$. El estuco

Profecia, la Obediencia y el Ministerio Sacerdotal, la Castidad y la Corrección Fraterna, el Celo Santo y la Constancia, la Virtud y el Honor, la Protección y el Nombre, la Dignidad y el Favor, el Misterio y el Ministerio, el Martirio y la Maravilla, la Soledad y la Sabiduría Divina, la Divinidad y el Espanto, la Fe y la Conmiseración, la Muerte de los Justos y la Bienaventuranza y el Auxilio y la Victoria.

18 Alonso Fernandez, Antonio, op. cit.

19 Sebastian, Santiago y Zarranz Domenech, M. ${ }^{\text {a }}$ Reyes, op. cit., págs. 109-132.

20 Referimos para esta comparación a cualquiera de las obras de los arquitectos Juan Pérez Castiel, Francisco Padilla, ...cuya diferente estética se puede comprobar consultando las publica- 


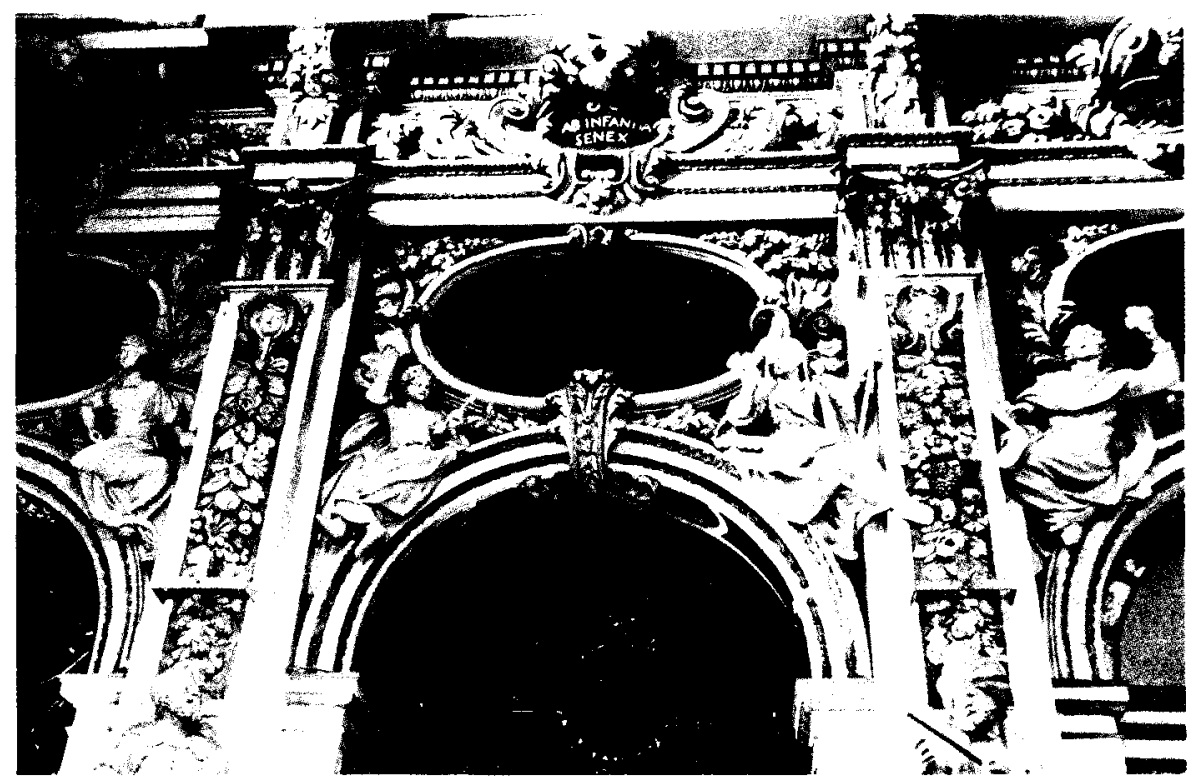

Fig. 4. Interior del Templo de los Santos Juanes. Estucos de Antonio Aliprandi y Giacomo Bertesi.

pasa de ser un modo de revocar dignamente un interior como en las iglesias de San Esteban o San Nicolás, a constituir un elemento activo dentro de la configuración del espacio sacro. La forma en que se explotan las posibilidades escenográficas del estuco en el interior de Santos Juanes es totalmente inusitada en la Valencia de la última década del xvı, y por ello hay que buscar la aportación de estos nuevos modos decorativos en los dos artistas italianos que, según Gil Gay, aparecen activos en la parroquia durante estos años, Bertesi y Aliprandi (Fig. 4).

El 18 de noviembre de 1696 los Electos de la Parroquia de San Pedro de la Catedral conciertan la construcción de nueva planta de dicha parroquia con el arquitecto Juan Pérez ${ }^{21}$, entonces maestro mayor de las obras de la Catedral ${ }^{22}$. Se plantea como una capilla cuadrada, de mayor enver-

ciones de carácter general que sobre esta época se han realizado, bien sea PINGARrón, Femando, Arquitectura religiosa del siglo XVII en la ciudad de Valencia, Valencia, 1998 o BéRCHEz, Joaquín, Arquitectura barroca..

21 El contrato transcrito por Pingarión, Femando, op. cit., págs. 675-679.

22 Véase Aldana Fernandez. Salvador, "El arquitecto barroco Juan Pérez Castiel", Boletín de la Sociedad Castellonense de Cultura. 1967, págs. 248-279. 
gadura que el resto de las capillas de la catedral, y cubierta con cúpula. La nueva obra, que iba a realizar las funciones de Capilla de la Comunión de la Seo, aparece como una renovación integral, cuyo proceso puede seguirse mediante las deliberaciones de los Electos de la Parroquia, registradas por el notario Gabriel Huguet, a través del cual se contratará y pagará a los artistas activos en la obra.

La obra de Juan Pérez Castiel, por la que recibe pagos hasta 1700 , debió limitarse a las labores de albañilería, ya que en dos ocasiones, una en 1699 y otra en 1701, los Electos de la parroquia contratan la obra de piedra con el cantero Domingo Laviesca ${ }^{23}$. Éste aparece cobrando desde 1699 hasta 1703, en unas ocasiones por conceptos que refiere a las capitulaciones, y en otras por diferentes obras, como las tapas de los sepulcros ${ }^{24}$, las mejoras en la obra capitulada ${ }^{25}$, el enlosado ${ }^{26}$, las losas con inscripciones ${ }^{27} \mathrm{o}$ el aguamanil ${ }^{28}$. La magnitud de la intervención de Domingo Laviesca en la realización del proyecto arquitectónico parece al menos tan importante como la de Juan Pérez Castiel como demuestra la cantidad de pagos recibidos y la visura que el 2 de febrero de 1703 llevaron a cabo de la obra de Laviesca los expertos Juan Pérez Castiel y Domingo Escrivá ${ }^{29}$, quienes encuentran varias mejoras sobre lo capitulado.

Como complemento a las obras de arquitectura se acometerán diferentes fases para dotar al interior de la construcción de una aspecto digno. La primera de ellas es la contratación del retablo el 2 de agosto de $1697^{30}$. El escultor que recibe pagos entre 1698 y 1701 por la obra del retablo es el conocido José Cuevas. El mismo José Cuevas recibe el último

23 Ambos contratos aparecen registrados en el baldufafi de Gabriel Huguet, Archivo de Protocolos del Patriarca de Valencia (APPV), signatura 27848. El primer contrato pertenece al protocolo correspondiente al año 1699,que se ha perdido, el segundo pertenece al protocolo de 1701 , que si se conserva. Este contrato aparece citado en PINGARRÓN. Fernando, op. cit., pero en la actualidad los folios en los que este autor sitúa el contrato se han perdido.

24 APPV, signatura: 8140, fol. 1602, 7 de noviembre 1702, Notario: Gabriel Huguet.

25 APPV, signatura: 8271, fo!. 169, 2 de febrero 1703, Notario: Gabriel Huguet.

26 APPV, signatura: 8271 , fol. 627,5 de junio 1703 , Notario: Gabriel Huguet.

27 APPV, signatura: 8271 , fol. 669,17 de junio de 1703, Notario: Gabriel Huguet.

28 APPV, signatura: 8271, fol. 694, 26 de junio de 1703, Notario: Gabriel Huguet

29 APPV, signatura 8271, fol. 167r-169r, 2 de febrero de 1703, Notario: Gabriel Huguet.

30 Pingarron, Fernando, op. cit., pág. 123 cita el documento de las capitulaciones con el escultor Vicente Rovira, y las sitúa en los folios 599r-609y. El mismo autor expone que para dicho retablo hicieron trazas Mosén Juan Pérez, Luys Fuster, March Angós, Vicent Artigues y Francisco Padilla, a quienes se otorga ápoca según consta en el baldufari de Gabriel Huguet En la actualidad los folios del protocolo 8267 de Gabriel Huguet correspondiente al año 1697 en los que se registran estas actividades se han perdido. Lo mismo ocurre con el pago a Vicente Vitoria por la traza y capítulos del retablo, que Fernando Pingarrón sitúa el 24 de noviembre de 1698. 
pago del retablo el 21 de junio de 1701, por las imágenes del mismo, así como por la obra de albañilería, "escultura de algeps», del anillo de la cúpula de la capilla y por la mesa de altar ${ }^{31}$. El 18 de junio Luis Fuster y Dionis Molins, ambos escultores, emiten dictamen sobre la obra acabada del retablo ${ }^{32}$, y encuentran varias mejoras sobre lo capitulado. El 8 de agosto del mismo año se contrata con el dorador Pere Ruiz el dorado del altar de José Cuevas ${ }^{33}$. En este contrato aparecen las características del retablo, que constaba de dos cuerpos ordenados mediante columnas y pilastras entre las que había espacio para lienzos pintados así como para las imágenes de Santo Tomás de Aquino, San Antonio de Padua, San Pablo y San Andrés esculpidas por Cuevas.

El embellecimiento de la parroquia sigue de forma imparable, y en las reuniones de los Electos se buscan continuamente modos de financiación. Se delega la misión de elegir a los artífices que participan en la decoración principalmente en Francisco Mascarell y Pertusa, Juan Bautista Folch y Vicente de Saboya, y ya desde temprana fecha se decide que uno de los elementos básicos del revestimiento del templo sea la pintura al fresco ${ }^{34}$ : "Item delliberen y determinen que si als elets de la present parroquia pare, que es pintas la dita capella, que ho puguen aquells fer en la millor forma que sia convenient, gastant tot lo que sia necesari" ${ }^{35}$.

En este sentido se decide contratar los servicios de Vicente Vitoria, canonigo de la Colegiata de Játiva según decisión de los electos del 27 de abril de 1698. La elección de éste se haría en contra del otro candidato a pintar los frescos, el pintor que en ese momento se hallaba decorando la bóveda de la Parroquia de San Nicolás, a la sazón Dionis Vidal, discípulo de Palomino que en el interior de esta parroquia llevaba a cabo un programa elaborado por su maestro ${ }^{36}$. Vicente Vitoria es uno de los personajes más destacados del medio cultural valenciano de finales del siglo XVII. Pintor y gran conocedor de temas artísticos por esta fechas había frecuentado las ciudades de Florencia y Roma, y, en Valencia, participa en algunas

\footnotetext{
APPV, signatura 8270 , fol. 591 v-593r, 21 de junio de 1701, Notario: Gabriel Huguet. APPV, signatura 8270, fol. 588v-590v, 18 de junio de 1701, Notario: Gabriel Huguet. APPV, signatura 8270 , fol. $826 \mathrm{r}-834 \mathrm{v}, 8$ de agosto de 1701, Notario: Gabriel Huguet. 4 Sobre el programa iconográfico de la capilla véase VILAPLANA ZURITA, David, «La antigua capilla parroquial de San Pedro de la Catedral de Valencia". Archivo de Arte Valenciano, 1986,

APPV. signatura 8267, fol. 840v-844v, 23 noviembre de 1697, Notario: Gabriel Huguet

36 Véase LLoRENS MONTORO, Juan Vicente, «Fr. Juan Tomás de Rocaberti y Vicente Victoria mentores de los programas pintados por Antonio Palomino en Valencia", en Archivo de Arte Valenciano, 1989, págs. 51-60, donde se relaciona a Vicente Vitoria también con el programa de los frescos de la Parroquia de San Nicolás.
} págs, 65-68. 
empresas artísticas que pueden considerarse entre las más innovadoras de su momento, como es el caso de la decoración interior de la parroquia de los Santos Juanes ${ }^{37}$. Por sus pinturas al fresco en la cúpula de la parroquial de San Pedro aparece otorgando épocas el 22 de junio, el 31 de octubre y el 5 de diciembre de $1698^{38}$.

Ya vimos como los parroquianos estaban dispuestos a no escatimar gastos en la nueva edificación, y así, en 1702, se requieren los servicios de Antonio Palomino ${ }^{39}$, quien pinta al óleo y al fresco las pinturas del retablo y aquellas que decoran los muros perimetrales de la capilla ${ }^{40}$. De nuevo encontramos en la renovación de la parroquial de San Pedro a uno de los participantes en la contemporánea reforma de la iglesia de los Santos Juanes. El ciclo de pinturas comenzado por Vicente Vitoria y continuado por Antonio Palomino se completará con cuatro lienzos situados a los lados del retablo pintados por Felipe Navarro en el mismo $1702{ }^{41}$.

La reforma de la parroquial de San Pedro se completó con un revestimiento de estuco, que es el que interesa al desarrollo de este artículo. El rico revoque de estuco blanco que cubre los muros de la capilla fue contratado con Antonio Aliprandi en 1700, tal como consta en el baldufari de Gabriel Huguet. Aquel aparece otorgando ápocas desde 1700, siendo la del 6 de junio de 1701 la primera que se conserva ${ }^{42}$, hasta el 22 de mayo de 1702. Se trata del mismo estucador, quien se define a sí mismo como milanés, que participa en el revoque de los Santos Juanes. Para llevar a cabo la obra de estuco se montaron andamios por parte del carpintero Miquel Esteve en 1701 y $1702{ }^{43}$, quien también realizaría, al mismo tiempo, los que necesitaba Antonio Palomino para pintar los frescos y reconoce que actúa como asistente de Aliprandi en el trabajo del revoque. El acabado final del revestimiento de estuco de la parroquia de San Pedro debió

37 BorulL, J., «La decoración pictórica de los Santo Juanes de Valencia. Un dictamen inédito de Palomino", Archivo de Arte Valenciano, 1915, págs. 50-58.

38 APPV, signatura 8268, fol. 621r-622r, 22 de junio 1698, Notario: Gabriel Huguet.

39 Además de las pinturas, hasta ahora no documentadas, de la Parroquia de San Pedro, Antonio Palomino pinta en Valencia los frescos de la parroquial de los Santos Juanes y la cúpula de la Virgen de los Desamparados, además de elaborar el programa que Dionís Vídal llevaría a cabo en la bóveda de la Parroquia de San Nicolás. Véase al respecto Aparicio Olmos, Emilio M., Palomino en Valencia, Tesis de Licenciatura de la Universidad de Valencia, 1954; ApARICIO OLMOS, Emilio M., Palomino: su arte y su fiempo, Valencia, 1966. En ambos se recoge la atribución a Palomino de los frescos y pinturas de caballete de la Parroquia de San Pedro. Véase también LLOrens Montoro, Juan Vicente, Antonio Palomino..

40 APPV, signatura 8140 , fol. $725 r-726 r, 15$ de mayo de 1702 , Notario: Gabriel Huguet.

41 APPV, signatura 8140, fol. 841v-842r, 17 de junio de 1702, Notario: Gabriel Huguet.

42 APPV signatura: 8270 , fol. $537 v-538 v, 6$ de junio 1701, Notario: Gabriel Huguet.

43 APPV signatura: 8270, fol, 572r-573r, 17 de junio de 1701, Notario: Gabriel Huguet. 
ser muy diferente al que en la actualidad se observa. El incendio de la capilla durante la Guerra Civil acabó con cualquier policromía al igual que desfiguró los frescos de Vitoria y Palomino. Sin embargo, gracias a los documentos, sabemos que originalmente los estucos combinaban el blanco de la obra de Aliprandi con el dorado aplicado por Pere Ruiz y Pere Ferrer ${ }^{44}$. Ruiz, el mismo que había contratado el dorado del retablo realizado por José Cuevas, seria quien aplicara los toques de dorado al estuco lúcido de Aliprandi, mientras que Ferrer proporcionaría el material. El contrato de dorado del retablo puede proporcionar algunas pautas sobre la delicadeza y minuciosidad con la que se afrontó el acabado de los ornamentos de la capilla. Se habla de imitación de telas, de "brocados picados", "brocados con flores", "campo esgrafiado con diferentes aguadas de colores", "cenefa de estofado», "horillo de Milán», ... en una voluntad decidida por crear un mundo rico de imitaciones, casi siempre textiles, que no encuentrarı comparación en obras contemporáneas. Todo ello se completa con referencias a la arquitectura, las columnas que se han de "colorir con sus cambiantes", "en la Capilla unas aristas que hay se ayan de hacer unos estofados dexando el campo de oro», o se habla de «matizar unos jaspes". De estas referencias se puede inferir que el ya de por sí rico revestimiento creado por Aliprandi estaría matizado por el color dorado aplicado con diferentes tratamientos, acentuando la presencia insistente y el carácter ilusionista del mismo, que se combinaría con la imitación de mármoles y jaspes (Fig. 5).

El acabado se asemejaría más al aspecto que ofrecen los estucos de Aliprandi en el presbiterio de El Milagro de Cocentaina, ya que los estucos de San Juan del Mercado también fueron afectados por el fuego y el encalado uniforme que presentan en la actualidad desmerece la opulencia que debieron mostrar (Fig. 6).

Otro de los espacios eclesiásticos, éste desaparecido, en donde tradicionalmente se ha visto la participación de Antonio Aliprandi, es en la Capilla de la Purísima Concepción de la iglesia de la Compañía de Jesús (en probable colaboración con Giacomo Bertesi, como ocurrió en San Juan del Mercado). Las noticias sobre este edificio son muy escasas debido a su derribo en el siglo xIX, pero el hallazgo de los pagos por la obra de la Capilla de la Purísima nos permitirá conocer algo más sobre esta construcción.

44 APPV, signatura 8270 , fol. 1215v-1216v, 6 de diciembre de 1701, Notario: Gabriel Huguet. Según Orellana, Marcos Antonio de, op. cit, pág. 471. Felipe Navarro pintó varios de los lienzos que ornaban el interior de la iglesia de San Juan del Mercado 


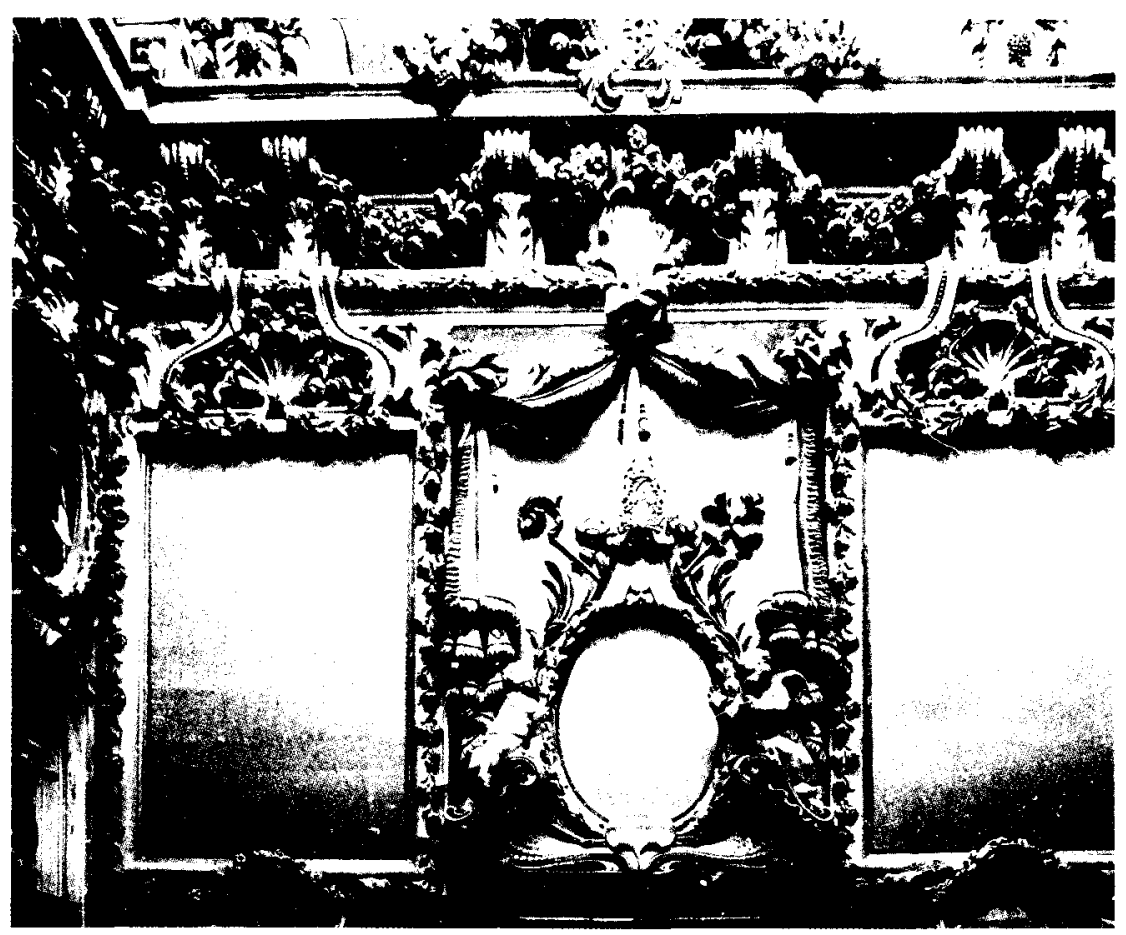

Fig. 5. Parroquia de San Pedro de la Catedral de Valencia. Estucos de Antonio Aliprandi. (Fotografía Joaquin Bérchez)

El 12 de enero de 1700 se efectúan una serie de pagos por parte del padre jesuita Bartolomé Pons por la obra de la capilla de la Purísima en la Casa Profesa. El primero de los artífices que aparece cobrando es Antorio Aliprandi ${ }^{45}$, quien es remunerado por todos los ornamentos de dicha capilla, aclarando que se trata de obra de estuco. De nuevo nos encontramos ante la renovación integral de un espacio sacro, ya que el mismo 12 de enero otorgan ápocas Claudio Blanch «lapicida», Fabián Izquierdo, dorador, Tomás Paradís, "faber lignarius», y Gaspar Martínez, albañil ${ }^{46}$. El acabado sería, pues, similar al de la Parroquia de San Pedro, es decir, estucos combinando el blanco y el dorado en una composición abigarrada de elementos de mucho volumen.

45 Archivo del Reino de Valencia (ARV), Protocolos Notariales, signatura 4465, sin foliar, 12 de enero de 1700, Notario: Francisco Causes.

46 ARV. Protocolos Notariales, signatura 4465, sin foliar, 12 de enero de 1700, Notario: Francisco Causes. 


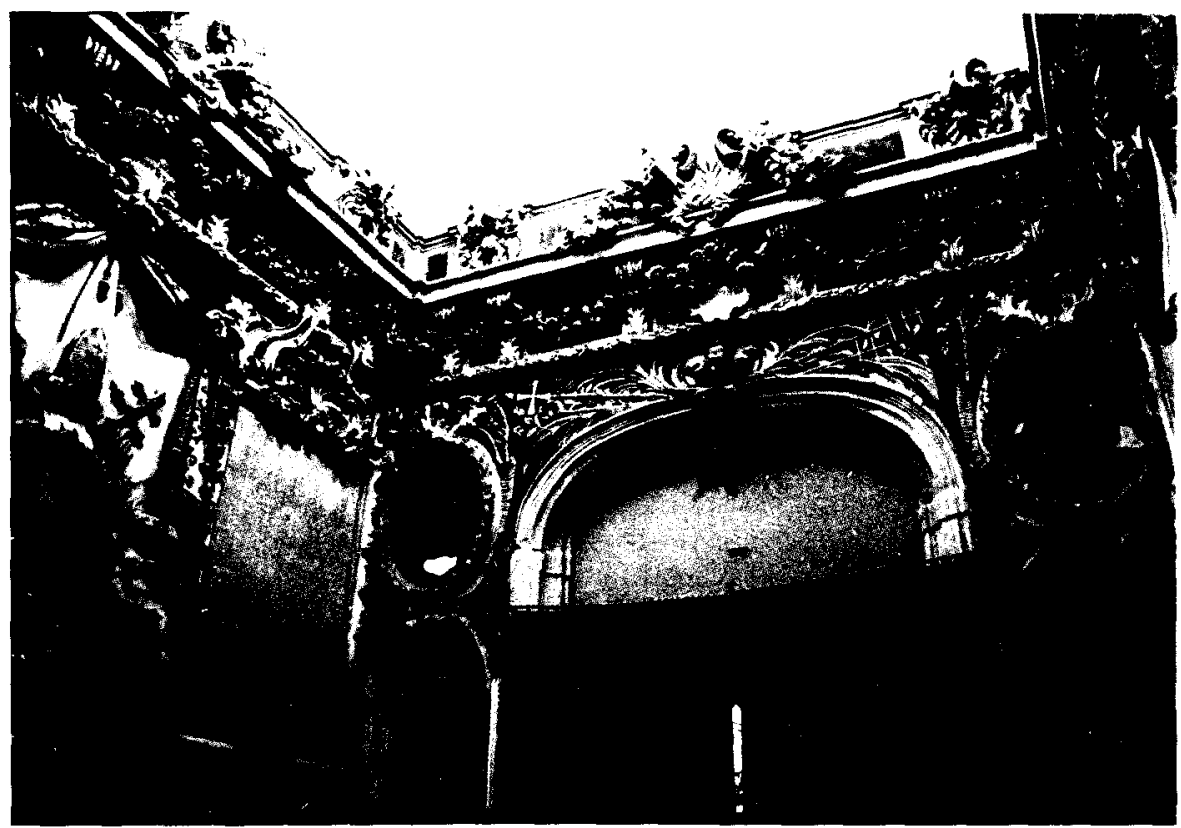

Fig. 6. Parroquia de San Pedro de la Catedral de Valencia. Estucos de Antonio Aliprandi. (Fotografía Joaquín Berchez).

Una indicación interesante sobre la capilla de la Purísima la encontramos en la tercera parte del Museo Pictórico, de Antonio Palomino, El Párnaso Español pintoresco laureado ${ }^{47}$, en donde, al componer la biografía del canónigo Vicente Vitoria, relata que pintó al fresco la Sacristia del desaparecido Convento de San Francisco, los frescos de la cúpula de la Parroquia de San Pedro, documentados, y las pinturas de la cúpula de la Capilla de la Purísima en la Casa Profesa. Esto hace que esta capilla, que, al parecer, se reedifica de forma integral, presente similitudes con las obras que se han nombrado anteriormente, y que de nuevo en esta capilla coincidan artistas que ya se encontraban activos en las obras de San Juan del Mercado y la Parroquia de san Pedro. Por ello, es fácil inferir que el aspecto final de la capilla de la Purísima sería similar al que presentaban originalmente estas dos parroquias, es decir una combinación de paños murales cubiertos con ricos estucos dorados de gran volumen, con techos pintados al fresco.

47 Publicada en 1724, se ha consultado la edición a cargo de Ayala MALIORY, Nina, Vidas, Madrid, 1986, págs. 385-388. 
La única obra de Antonio Aliprandi que hasta el momento se había documentado son los adornos y retablo del templo del Convento de la Virgen del Milagro en Cocentaina ${ }^{48}$. En esta obra corresponde a Aliprandi ordenar la cabecera del templo alrededor del camarín de la titular. En el pequeño camarín encontramos elementos ornamentales relacionados con el estucador lombardo como las conchas rugosas y las sartas florales, pero el grueso de la obra de esta remodelación se encuentra en el retablo que mira al templo. Éste se organiza mediante pilastras compuestas pareadas en torno al hueco central. Entre los pares de pilastras aparecen ménsulas con escultura de bulto, en la línea de lo realizado pocos años antes en el interior de los Santos Juanes de Valencia. El friso que recorre toda la capilla mayor se decora con guirnaldas florales, y sobre la cornisa apoyan angelotes dorados. La mayor concentración decorativa se encuentra sobre la cornisa, a plomo sobre la imagen titular, donde se ha tallado un enorme dosel textil. Sin embargo, lo que probablemente hace más característica a esta obra, es la inclusión de un transparente bajo el dosel de estuco. Se trata, probablemente, de la primera vez en territorio hispano que se explotan las posibilidades escenográficas de la luz ${ }^{49}$, horadando la bóveda para crear un foco lumínico contra el que destaca la imagen del Espíritu Santo (Fig. 7).

El resultado obtenido por Aliprandi en el presbiterio de Cocentaina es, probablemente, el más conseguido de su actividad valenciana. Se combinan con éxito recursos arquitectónicos, escultóricos y ornamentales y además se incluyen por primera vez efectos lumínicos que lo vinculan a experiencias romanas de carácter berninesco. El efecto es reforzado por la policromía y el dorado, aplicados diestramente por Pedro Ruiz, según ha documentado Inmaculada Vidal. Los dorados y los toques de color en las esculturas exentas se combina con ricas imitaciones de mármoles y jaspes en los elementos arquitectónicos, técnica no excesivamente desarrollada en el medio valenciano hasta la llegada de Aliprandi. Este Pedro Ruiz es el mismo dorador que le asistiera en la terminación de los estucos de la parroquia de San Pedro de la Catedral de Valencia, en la que se suponen unos acabados originales similares a los de Cocentaina. La presencia de este dorador, cuya destreza en el manejo de la policromía y el dorado,

48 Vidal Bemabé, Inmaculada, Retablos alicantinos del Barroco (1600-1780). Alicante, 1990. págs. 113-115.

49 Rodriguez G. de Ceballos, A., "La huella de Bemini en España", en Hibbard, Howard, Bernini, Madrid, 1982. págs. XIV-XVI. En este texto se nombran los transparentes de Toledo y Cuenca, obras muy posteriores. La obra de Aliprandi en Cocentaina ha sido destacada por BERCHEZ, Joaquín, Arquitectura barroca..., pág. 86. 


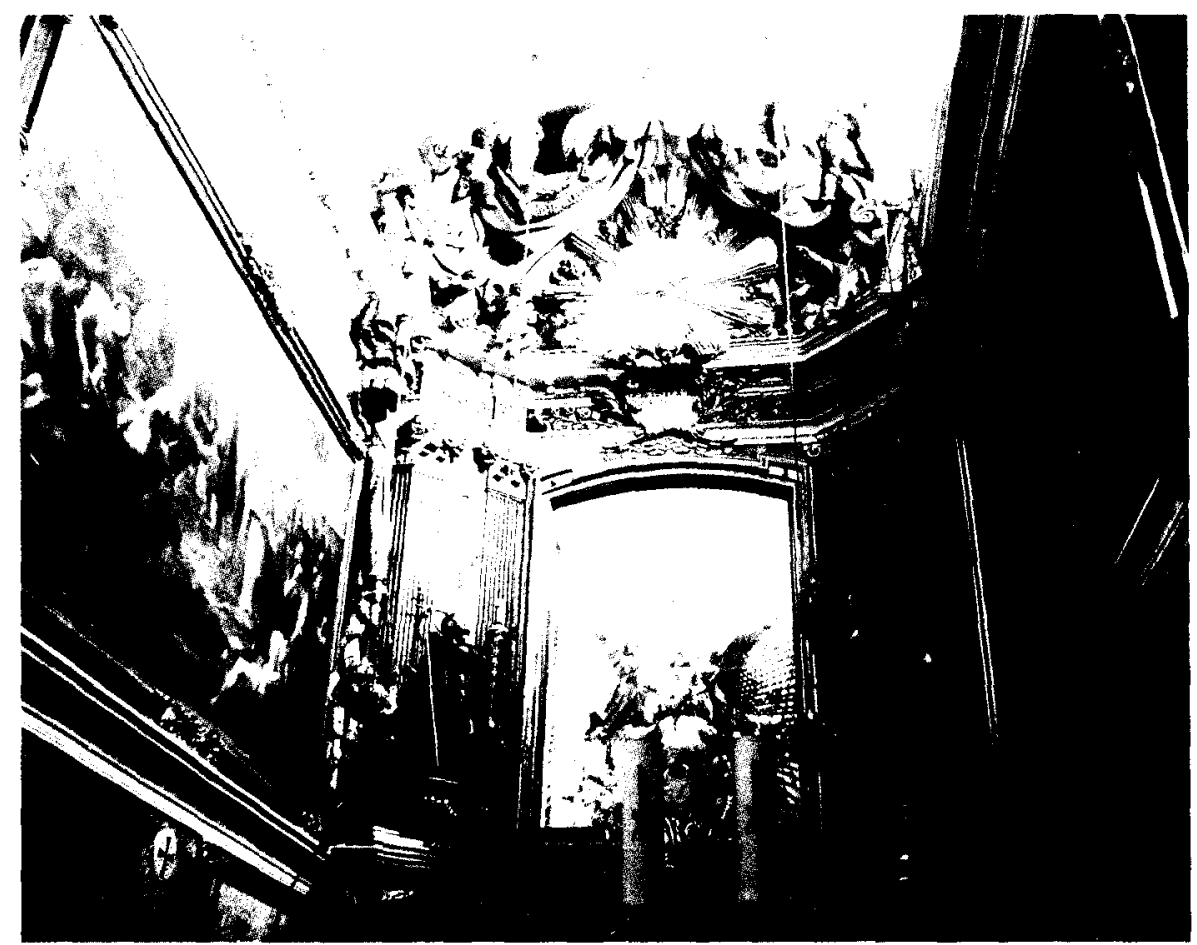

Fig. 7. Cabecera del Templo del Milagro de Cocentaina. Estucos de Antonio Aliprandi.

así como en la imitación de jaspes, patente al analizar el contrato del dorado en la parroquia de San Pedro, sugiere la existencia de un círculo de artistas valencianos alrededor de los artífices extranjeros llegados a Valencia en torno a 1700 . No sólo Palomino y Vitoria, sino también artesanos como el dorador Pedro Ruiz se moverán de forma continuada en el entorno de las obras de Aliprandi, siendo su obra posterior fundamental para entender la difusión y el mayor o menor éxito de los presupuestos estéticos del lombardo (Fig. 8).

Por último, y conociendo algo más los modos de hacer de Antonio Aliprandi como un adornista especializado en revestimientos de estuco, cabe enfrentarse a una obra que se llevó a cabo durante los años en torno a 1700 y que supone también un distanciamiento de la práctica artística autóctona. Nos referimos a la decoración de estuco del salón principal de la casa solariega conocida como "Huerto de Pontons», que se encontraba en Patraix y de la que se conservan fotografías de principios de siglo. Orellana atribuye estos estucos a la mano de Giacomo Bertesi, 


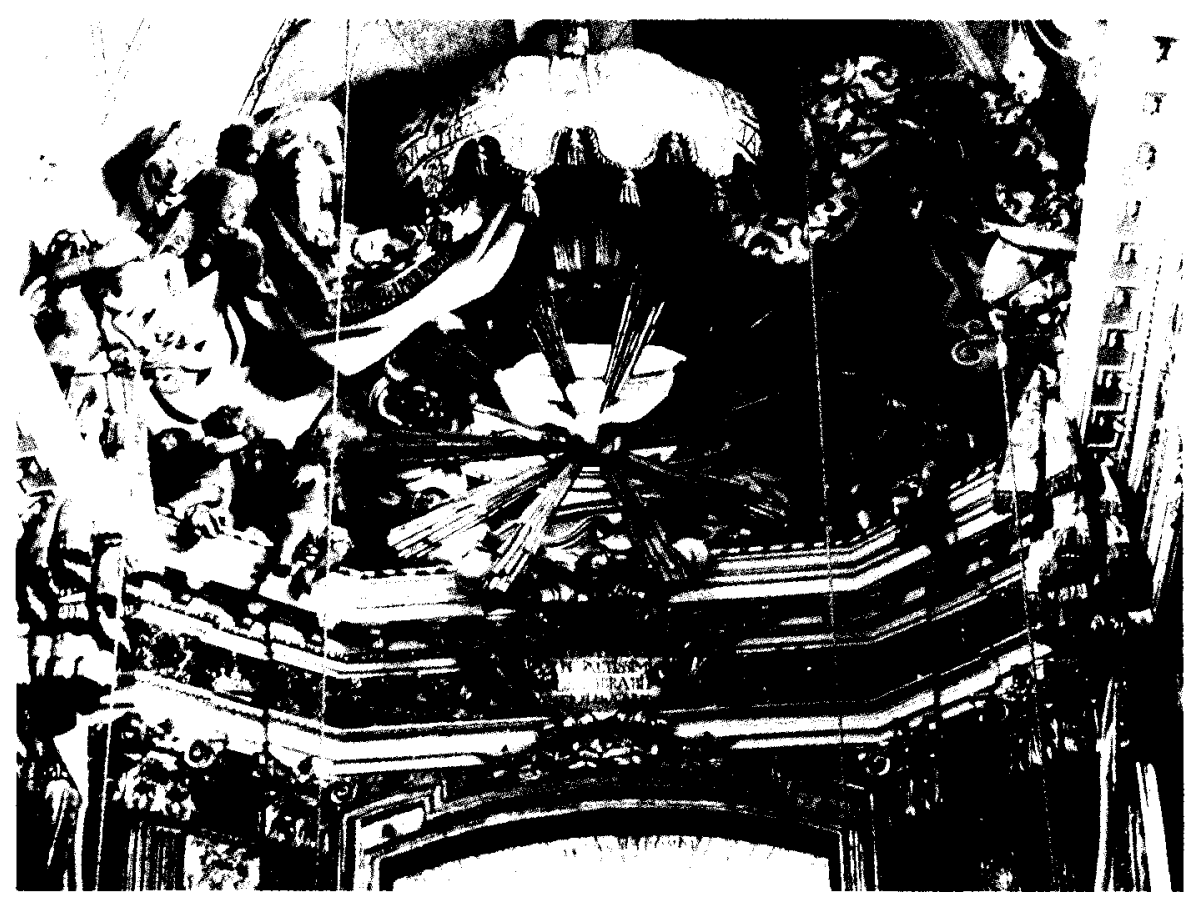

Fig. 8. Cabecera del Templo del Milagro de Cocentaina. Estucos de Antonio Aliprandi.

mientras que las pinturas las asigna a Antonio Palomino o a Juan Bautista Bayuco ${ }^{50}$. Pontons, personaje destacado de la cultura valenciana del momento, había decorado los jardines de su villa con esculturas del genovés Giacomo Antonio Ponsonelli ${ }^{51}$, escultor del púlpito de San Juan del Mercado, contrato que había conseguido a través del canónigo ${ }^{52}$. Por las imágenes que se conservan del revoque de estuco de la villa de Patraix, con profusión de guirnaldas florales, imitación de textiles en forma de baldaquino y marcos de laurel para pinturas, la obra se corresponde totalmente con los modos de hacer de Antonio Aliprandi. Las inquietudes artísticas del canónigo Pontons y su relación con algunas de las obras en las

50 Orellana, Marcos Antonio de, op. cit., pág. 214

51 Sobre la villa de Pontons en Patraix y las esculturas y salón principal véanse AMV: Biblioteca Serrano Morales. Fuster y Membrado, Sucesos memorables de Valencia, tomo /, pág. $918 ;$ y la nota 6 .

52 Gll Gay, Juan, op. cit., 1909, pággs. 52-53. Sobre la obra de Ponsonelli en Valencia véase Ferran Salvador, Vicente, "Un escultor barroco. Jacobo Ponzanelli", en Almanaque de las provincias, 1947, págs. 585-590. 
que participó Antonio Aliprandi hacen que no resulte extraña la posibilidad de que contratara sus servicios (Fig. 9).

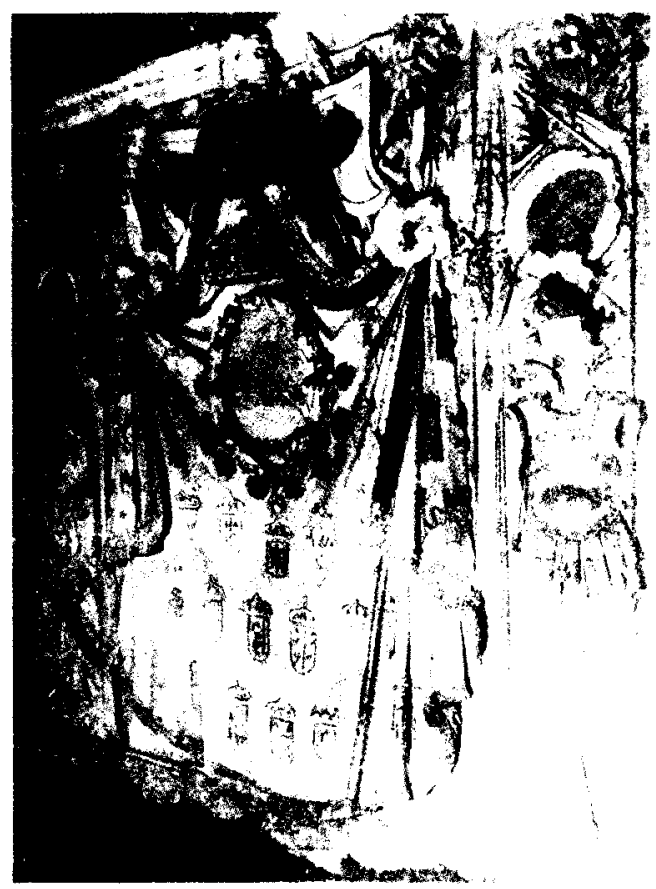

Fig. 9. Salón del desaparecido "Huerto de Pontons" en Patraix (Valencia). 
